Editorial

\title{
The Importance of Transport for Social Inclusion
}

\author{
Janet Stanley ${ }^{1, *}$ and John Stanley ${ }^{2}$ \\ ${ }^{1}$ Melbourne Sustainable Society Institute, University of Melbourne, Melbourne, VIC 3010, Australia; \\ E-Mail: janet.stanley@unimelb.edu.au \\ 2 Institute of Transport and Logistics Studies, Business School, University of Sydney, Sydney, NSW 2006, Australia; E-Mail: \\ john.stanley@sydney.edu.au \\ * Corresponding author
}

Submitted: 23 November 2017 | Published: 28 December 2017

\begin{abstract}
Links between mobility, social exclusion and well being, and matters related thereto, have been an important focus of research, planning and policy thinking in the land use transport field for about the past two decades, in places such as the UK, Australia, South Africa, North America and parts of South America. This introductory paper to the journal volume on Regional and Urban Mobility: Contribution to Social Inclusion summarizes some of the key literature in the field during that period, illustrating how research sometimes takes a place-based approach and at other times focuses on groups of people likely to be at risk of mobility-related social exclusion. The ten articles in this journal volume explore aspects of these relationships, mainly through the lens of at risk groups, across a number of social-spatial settings. Articles draw on case studies from the Philippines, UK/Germany, UK/Colombia, Lisbon, Gilgat-Baltistan, Turkey and Japan, providing a broad set of contexts. The different language and frameworks used by researchers from different professional backgrounds, as illustrated in this volume, highlights some of the barriers that need to be confronted in progressing policy to improve the lot of people experiencing mobility-related social exclusion.
\end{abstract}

\section{Keywords}

cars; mobility; public transport; social inclusion; transport; urban design; walking; youth

\section{Issue}

This editorial is part of the issue "Regional and Urban Mobility: Contribution to Social Inclusion", edited by Janet Stanley (University of Melbourne, Australia) and John Stanley (University of Sydney, Australia).

(C) 2017 by the authors; licensee Cogitatio (Lisbon, Portugal). This article is licensed under a Creative Commons Attribution 4.0 International License (CC BY).

\section{Introduction}

The ability to be mobile has always been important to humans, facilitating vital connections with people and places. The culture and functioning of a society or community, shapes, and is shaped by, the need, ability and choices for travel: the distance travelled, the means of travel, who travels and why. In agriculturally-based economies work was located within an acceptable travel time from where the person lived, commonly by walking or perhaps use of an animal for transport, defining the spatial limits to a village's agricultural pursuits. Thus, housing and work environments were closely located, as were common spaces used for the attainment of goods and services and to meet other needs, such as 'religious' practices and social interaction. The way that trip numbers decrease with increasing travel times, and how this might reflect social exclusion, is considered in the article by Cao, Stanley and Stanley (2017) in this journal edition.

The movement from a small agricultural economic base to industrialisation, work specialisation and the movement of people from rural areas to live in urbanised areas, changed travel requirements and increased travel distances but not necessarily travel times, as illustrated by work on travel time budgets (e.g., Marchetti, 1994; Zahavi, 1979). To meet this need, the car has increasingly been the dominant form of transportation in industrialized countries since the 1950s, and in the last few decades there has been rapid growth in car use in industrializing countries. It is estimated that there will be 
more than two billion cars globally by 2030 , representing a $250 \%$ increase in less than 30 years (Sperling \& Gordon, 2009). Motorisation is increasing at more than $10 \%$ per annum in many cities in industrializing countries (Gakenheimer \& Dimitriou, 2011).

\section{The One-Sided Transport Option}

As car ownership increased for most people, so society became increasingly re-structured to accommodate the private car, roads widened and freeways built, shopping and service centres with parking surrounding them, reflecting a predict-and-provide transport planning mentality. As a result, it has become increasingly harder to travel by other means-walking, cycling or public transport. One of the authors recently foolishly attempted to walk from her hotel accommodation to a meeting in nearby Parliament House in Canberra, Australia's national capital, a feat achieved with considerable detours to cross a freeway and avoid fences and necessitated hiking over large expanses of long wet grass!

Public transport is often in scarce supply outside the central parts of cities. In rural areas and in many cities in industrializing countries walking and cycling have become increasingly difficult and often dangerous and many people rely on informal transport. Movement corridors are made for vehicles. In most urban settings houses are built facing roads instead of bike paths or walkways. Provisions like traffic signals at intersections are timed for the maximum benefit of vehicles, pedestrians sometimes having to wait a long time to cross a road, having to watch out for turning traffic and, unless taken at a running pace, may need two light cycles to cross some roads. Bus stops commonly have no (or minimal) seating and there are few charging stations in urban areas for people on gofers (Stanley, Stanley, \& Hansen, 2017).

In industrialized countries, and now in many industrializing countries, the growth in car use is defining urban structure and establishing a trajectory of (path dependent) private vehicle-based solutions. In Melbourne, from 1875-1975, for example, a pattern was established of suburban high-status living and inner-city slums, due firstly to rail transport, then the growth of car ownership, underpinned by the wide spread of employment opportunities. Since that time, structural economic change has led to growth of high productivity/high income knowledge economy jobs in inner areas and loss of manufacturing jobs in middle/outer suburbs. Inner urban land values are soaring in response, densities increasing and lower income households are increasingly 'forced' to the outer fringe or to small apartments in inner areas. The increasingly gentrified inner area receives the benefit of high quality public transport services and outer suburbs are increasingly becoming centres of disadvantage, largely reliant on car travel, with low public transport service levels.

O’Brien, García Vélez and Zaltz Austwick's (2017) article offers insights into a growing area of interest in relation to mobility and social inclusion: the impact of spatial urban design, particularly roads and streets, on community connections, and how the built environment impacts on movement patterns and influences feelings about the spatial areas of their community and sense of place. Interestingly, the authors went straight to seek the views of a group seen by many researchers the group at greatest risk of social exclusion as a result of problems around mobility: children and youth. O'Brien et al. (2017) sought the opinion of youth (11 to 19) in two major cities, Liverpool, UK, and Medellin, Colombia.

The functional importance of transport is mirrored in its significance in household expenditure patterns. In the UK, for example, transport is the largest single household expenditure item, marginally ahead of housing and accounting for $13.7 \%$ of average weekly household expenditure (Office of National Statistics, 2017). In the US and Canada, transport is the second largest component of household expenditure, representing $15.8 \%$ of consumer expenditure in the US (Bureau of Labor Statistics, 2017) and a high $19.4 \%$ in Canada (Statistics Canada, 2017). In both those countries, housing is the only sector with a higher expenditure share. In Australia, transport accounts for $14.5 \%$ of household expenditure (Australian Bureau of Statistics, 2017), the third highest expenditure share (behind housing, and food and beverageswe Australians are very hospitable!). In countries that are less car dependent and where public, informal and active travel play greater roles, transport represents a smaller proportion of household spending (e.g., $6.2 \%$ in the Philippines and $11.2 \%$ in Japan) (Philippine Statistics Authority, 2017; Statistics Japan, 2017).

The high proportions of household spending that goes on transport in countries like Canada, the US, Australia and in rural areas of the UK, particularly where settlement densities are low and car dependence high, has led to the idea of 'forced car ownership' (FCO). In such settings, people generally have little alternative to buying and using a car to be able to participate in the opportunities available in their society, because of a lack of alternative mobility choices (Currie \& Senbergs, 2007). With housing usually number one or two for household expenditure share and house prices increasing strongly in many economically successful cities (e.g., Vancouver, Melbourne), the notion of 'forced car ownership' and its associated stresses is highly pertinent for contemporary transport and social inclusion policy.

In this volume, Mattioli (2017) explores FCO in a comparative study of the UK and Germany, extending it to include consideration of potential economic stresses. He finds that people subject to FCO have lower overall levels of social exclusion and material deprivation than households who cannot afford cars but are worse off than 'car deprived' people in a number of domains, including inwork poverty and fuel poverty. Enforced lack of durables is found to be rare among FCO but their levels of economic strain are very close to those of other materially deprived households, despite higher incomes. The authors conclude that more compact settlement patterns 
should assist to reduce problems of FCO but these need to be complemented by policy measures in other sectors, such as housing, employment and welfare.

In places such as the UK, Europe, Canada and the US, there is a recent movement against low density development patterns associated with car dominance, with projects such as traffic calming, streets opened to pedestrians, and improving and greening open and public spaces in many cities increasingly common, located within a compact city development framework. Aspects of this trend are also being seen in Australian cities.

\section{Social Inclusion Implications of a Lack of Transport}

Land use patterns associated with high levels of car dependence have systematically disadvantaged some people, overlooking their travel needs. New urban fringe developments and even a move towards peri-urban settlements offer the most affordable housing for many people in industrializing countries and migrant families, newly established families (first home buyers) and those with a low income, such as sole-parent families, in industrialized countries. Declining investment in transport infrastructure and poor job generation in fringe suburbs that frequently lack transport connections to areas of major employment and other services, is a major problem in terms of entrenching social exclusion (National Institute of Economic and Industry Research, 2010).

Transport in rural areas is far more car dependent and the car plays a vital role in supporting social inclusion in rural and regional areas, particularly in countries like the US, New Zealand and Australia. For example, in Australia, public transport service availability was found to be between five and six times higher in metropolitan Melbourne than in a major Victorian region (Currie \& Delbosc, 2011). Some $24 \%$ of surveyed regional respondents indicated that there were activities they could not do because of transport problems, compared to $15 \%$ in the metropolitan area. Not surprisingly, there was a higher level of risk of social exclusion among regional residents than their metropolitan counterparts. The role of regional public transport in supporting social inclusion is notable (Stanley \& Banks, 2012).

Regional and rural people usually find a range of ways to adjust to a lack of local/regional public transport opportunities: buying additional cars (with problems of FCO); walking long distances; undertaking less than optimum negotiations with local options (such as the more expensive local store); establishing support and reciprocity arrangements with others; and modifying or going without some needs. Walking is used for about one-third of all trips in African cities and up to $90 \%$ of trips in smaller and poorer cities in Asia (Cervero, 2013a, 2013b). To help fill this travel hole, paratransit or community transport has become established in most industrialized countries. While this meets some needs for some people, it often tends to be exclusionary in itself, removing control of movements away from individual decision- making and being limited in accessibility options. In industrializing countries, informal transport options meet many transport needs for those at risk of social exclusion. This fulfils a need for many, but often at the cost of safety and pollution (Cervero, 2013a).

\section{The Interface between Transport, Social Inclusion and Wellbeing}

Internationally, over the last decade and a half or so, there has been interest in the unequal distribution of transport mobility benefits between different social groups and/or different areas, particularly as this relates to people without private car access in communities that have become increasingly car-dependent. The Social Exclusion Unit (SEU) popularised this recent awareness of the social value of transport, exploring accessibility barriers that make it difficult or impossible for people to participate fully in society (SEU, 2003). Also, US Federal public transport assistance, through the Safe, Accountable, Flexible, Efficient Transportation Equity Act, targeted employment access, elderly individuals and individuals with disabilities (SAFETEA, 2005). Such work builds on earlier interest in access for people with disabilities.

Researchers such as Mollenkopf, Marcellini, Ruoppila, Szeman and Tacken (2005) added a focus on wellbeing impacts of mobility opportunities for older people to the evidence base on transport, inclusion and wellbeing. Australian research then demonstrated how mobility improvements can reduce risks of social exclusion and enhance wellbeing for those at risk of social exclusion and that a high unit value can be imputed to such mobility improvements, this value increasing as household income of the beneficiary reduces (Stanley, Hensher, Stanley, \& Vella-Brodrick, 2011).

Despite this broadening approach to social goals of transport, there is still only limited work on social goals in transport and the policy that needs to be put in place to support these. SEU (2003) gave emphasis to the need for accessibility to a number of specific services which they nominated: work, health services, shopping, school and to a lesser extent, leisure activities. In summary, the SEU identified five transport accessibility solutions that are likely to facilitate social inclusion. These are:

1. Increasing the availability of, and reducing the physical barriers to, public transport: this deals with circumstances where public transport is either not on offer or not able to be utilised by a person due to factors such as steps to board a bus or tram;

2. Making transport more affordable: this particularly targets people who are socially excluded for reasons of low income;

3. Reducing the need to travel, by bringing services to people or changing the location of services;

4. Changing the perception that public transport is not safe; and, 
5. Widening travel horizons: people on lower incomes, for example, were found to often be less prepared to travel as far to reach work as those on higher incomes.

Australian regional and urban research found that groups of people at risk of social exclusion tend to have relatively lower rates of trip making than others (Stanley et al., 2011). That work proposed recommendations in five main areas, generally in line with the accessibility approach of the SEU:

1. Public transport service enhancements: the study proposed a set of minimum service standards for the route bus system in existing urban areas and in growth suburbs (hourly services on seven days a week, for at least 12 hours a day and longer on some days). It found that this initiative would benefit large numbers in most of the transport disadvantaged groups studied, providing improved travel options for many of their desired activities;

2. Marketing of public transport services: relevant initiatives include awareness programs for seniors, dealing with racism on public transport and extending two-hour tickets to three hours, the latter to allow greater activity linking at reasonable cost;

3. Regulatory reform: greater flexibility in use of the area's school bus system by transport disadvantaged (and other) groups was recommended, to enhance accessibility and improve efficiency of resource use;

4. Transport system planning: restructuring transport planning, to focus on needs identification for improved accessibility rather than on individual transport modes; and,

5. Research: improving understanding of the direct and indirect linkages between transport disadvantage, social exclusion and wellbeing.

Most accessibility planning nominates activities which it is thought people 'should' be accessing, which typically includes employment, education, shopping and such like. Australian findings suggested, however, that transport may have an important role in facilitating the development of social capital and community strengthening, both being a means of facilitating improved personal wellbeing, which is often not recognized by accessibility planning approaches. For example, social capital is created through interpersonal contacts. Implied in this is the need to 'access' people. This can be done through electronic media, but face-to-face contact is still the most common means used for socialising, as evidenced by the plethora of coffee shops, cafes, nightclubs and other less formal social contacts. Face-to-face contacts build trust and deeper relationships. The literature does not consider how this access is best achieved, however face to face contact seems likely to be an important component. Thus, to create the possibility of contributing to var- ious forms of social capital, a person usually needs to be mobile, through car travel, public transport, walking or other means.

Further investigation of the role of mobility in reducing social exclusion looked at the more subtle but important positive outcomes that can arise through the simple ability to be mobile, beyond the meeting of basic needseducation, employment, health and access to supplies. Empirical research showed that mobility enables individuals to accumulate social resources and obtain skills, thus gaining a sense of satisfaction, positive emotions and mental health (Vella-Brodrick \& Stanley, 2013). The skills of environmental mastery, positive relationships with others and self-acceptance are all developed (Ryff, 1989). This creates an upward spiral of positive affect that promotes more sustained wellbeing, and mobility is a means of improving mental health. Such mobility is particularly important for youth in isolated regions who lack bridging social capital and risk loss of self-esteem, confidence and risk developing helplessness traits and continuing inter-generational social exclusion (Stanley \& Stanley, submitted for publication). Thus, these less direct pathways of the value of mobility to those at risk of social exclusion can offer social and economic benefits, reducing the need for welfare support and health services and give rise to increases in productivity.

\section{Capabilities and Primary Goods}

The literature on social inclusion often includes discussion from major philosophers such as Rawls (1971), Sen (1993), and Nussbaum (1999), discussing social justice and the requirement for all people to be able to meet their needs in order to achieve wellbeing. Needs range from physiological requirements, safety, relationships, to self-esteem and self-actualisation. Mobility plays a vital role in enabling people to meet these objectives and be included in a well functioning society.

In the current volume, Hickman, Cao, Mella Lira, Fillone and Bienvenido Biona (2017) apply a capabilities framework to help understand travel as between high and low-income neighbourhoods in Manila. This is useful because there have been few such attempts to operationalize the capabilities approach in a transport/travel setting. The article distinguishes between what people might be able to access (capabilities) and their actual travel, which the authors term 'functionings'. Hickman et al. (2017) find significant differences by gender, age, income and neighbourhood, with social equity implications. The authors note that a capabilities approach is empirically difficult but offers opportunities to better incorporate social considerations alongside economic and environmental factors in a travel setting.

\section{Who Is at Most Risk?}

Discussion of the population groups most likely to be at risk of social exclusion due to relatively poor mobility op- 
portunities typically highlights older people, youth (especially young people living in rural settings), people with a disability, people with language difficulties (e.g., recent arrivals), those on low incomes, and those with little or no car access, with women and single parents also sometimes included (Currie \& Delbosc, 2011). People exhibiting multiples of these characteristics seem likely to be at relatively higher risk. The authors' current research also suggests that pre-school children should be added to this list, particularly in regional Australia, because of the demonstrated high lifetime costs that are potentially associated with being unable to attend pre-school. More generally, this volume includes a large number of presentations that focus on particular types of people who are more likely to face risks of social exclusion due to their mobility circumstances.

Akyelken (2017) explores how gender affects mobility-related economic exclusion in industrial zones in Turkey. The author uses a mixed methods approach to explore how men and women from different social backgrounds access industrial zones, to identify specific constraints that women face in accessing economic opportunities. Women's socioeconomic and educational backgrounds emerge as important predictors of commuting patterns and access to the industrial zones. The study confirms that gendered daily travel patterns are a useful unit of analysis for investigating unequal access to economic opportunities. Employer perceptions of women's work spaces and time use also emerge as important considerations.

Cao et al. (2017) seek to identify areas of relative transport disadvantage within an archipelagic region of the Philippines. The authors assess constraints that limit travel between cities and townships by undertaking a small travel behavior survey and developing a trip generation/distribution model, applied across four population centres, to observe how physical isolation from larger centres of social confluence can be reflected by lower trip volumes and associated increases in risks of social exclusion. The article estimates how faster inter-island travel times will impact on inter-island travel opportunities for people living in areas of relatively greater transport, social and economic disadvantage, with the expectation of associated reduction of exclusion risks and improved economic opportunities.

Yamamoto and Zhang (2017) examine mobility challenges facing elderly people in rural Japan, where declining population numbers, a shortage of public transport services and reducing opportunities for being driven by elderly male family members or friends are combining to increase exclusion risks. The article illustrates how cultural attitudes and social norms affect the ways in which older people manage their mobilities. An interesting question is whether the tendency of the older people who were surveyed to 'accept', somewhat resignedly, their circumstance of likely reduced mobility should determine policy responses, or whether policy makers should actively seek to promote adequate mobil- ity opportunities for all, to ensure inclusion. Our view is firmly in the latter camp.

Hussain, Fisher and Espiner (2017) use a qualitative approach to identify a range of impacts associated with development of Karakoram Highway in the remote Gilgit-Baltistan region, which is administered by Pakistan. Development of the road has underpinned accelerated growth in population and tourism in particular, in this mountainous region. Consultations suggest that this has reduced the region's isolation, broadened employment and income generating opportunities and improved access to education, healthcare and goods and services. People's knowledge of surrounding areas and of other cultures has increased, associated with increased travel opportunities and the influx of tourists. The authors argue that these impacts are indicative of greater social inclusion. Conversely, some respondents to the study's surveys suggested that the road had altered the peace in the area (which was previously a single ethnic group with local governance) and others thought that there 'has been a decrease in love, respect, and relationship' and a reduction in the old sense of community. The authors recognize this as a simultaneous reduction in inclusion, at one scale, alongside an increase at another.

Migration is the focus of two papers in the volume. Viry, Ganjour, Gauthier, Ravalet and Widmer (2017) assess associations between social visits and migrants' social capital, from a Swiss data set, with migrants defined by distance between birthplace and place of residence (i.e., not necessarily inter-country migration). Implicit in the analysis is that a higher level of social capital will mean a higher chance of social inclusion. As expected, they show that migrants have more spatially dispersed networks. These are associated with higher numbers of emotional support ties, compared to those with spatially close networks, and higher bridging social capital. Trust, however, declines as network spatial dispersion increases, perhaps partly reflecting the relatively greater influence of bridging social capital, compared to bonding capital, within the survey respondents' social capital stock, as network spatial dispersion increases. Bonding social capital tends to be associated with closer networks. Contrary to their expectations, the authors conclude that distant social visits have relatively little impact on social capital, across a range of social capital indicators. They suggest this result may be due to social visits being an insufficient indicator of the factors that contribute to the process through which family and friendship networks build norms of solidarity and reciprocity and a strong sense of togetherness at a broader spatial scale.

Buhr and McGarrigle (2017) discuss migrant mobilities and use of space in Lisbon, from two perspectives. They first look at migrants' urban knowledge and skills and how they employ them to use Lisbon's resources and then consider some of the ways place-specific urban resources of a religious nature sustain, and are sustained by, various mobility practices. Structural constraints are revealed by these examinations. People attending a Sikh 
Gurdwara and suburban mosque provide case study material. Outer urban migrants faced a poor range of work opportunities when their primary employment (in construction) finished, their migrant status compounding the narrow employment choices found in the outer urban parts of the city (similar to challenges faced by people in outer low density cities in Australia and North America). The local religious network of the mosque provided supporting bonding social capital (although the authors do not use this terminology). In contrast, bridging social capital from the Sikh community provided expanded migrant employment choices, partly reflecting its more accessible location within Lisbon. Networks were essentially local with the suburban fringe religious community but wider for the more accessible Sikh community. Locational and religious influences are jointly working on migrant mobilities, experiences of the city and associated opportunities for inclusion.

Transport disadvantage and wellbeing (defined as including measures of social exclusion) of rural high school students in Japan is discussed by Perez-Barbosa and Zhang (2017), with a particular focus on teasing out challenges facing students living in de-populating areas. High school students in three areas of declining population and one of growing population in Hiroshima Prefecture provide the study sample base. The authors find that students living in a depopulating area generally experience longer school trips and rely more on public transport, conditions they define as indicators of transport disadvantage, associated with lower levels of self-reported wellbeing. Lifestyle habits were found to be healthier in the non-depopulating sample, who also performed better on a range of measures the authors use to suggest social inclusion (health condition, participation, accessibility, social support). Conversely, students attending high schools in rural de-populating areas rated more highly, in inclusion terms, on volunteering and enjoyment of a natural lifestyle, matters that are commonly associated with residential choices associated with a rural lifestyle. Disentangling residential location choices and associated available modal options means household decision hierarchies are important in understanding key associations with wellbeing and social inclusion/exclusion.

\section{The Value of this Edition}

This edition of Social Inclusion offers important insights into the association between social inclusion and the ability to be mobile. It offers perspectives on a wide range of disadvantages that have been created by mobility problems, the value of mobility to individuals, communities and society more generally, and possible mobility solutions to facilitate inclusion. It reveals some of the complexities of the subject that now attracts a range of disciplines. This edition has the value of showing the breadth and importance of the topic, but also shows that there is a long way to go to get common language and understandings about the concepts and build a coherent theo- retical base. Yet without this development clarity, policy development will not be clear or persuasive.

While this edition offers insights into social exclusion in industrialized countries, particularly those in rural locations and migrants, importantly, it opens up new areas. The Sustainable Development Goals and the New Urban Agenda promoted by the United Nations, and widely being adopted, bravely talk about the need for social inclusion (United Nations, 2015). However, there is little knowledge on this problem in general in industrializing countries and almost no work on the important associations between social inclusion and transport. The two articles based in the Philippines and the Gilgit-Baltistan article in this edition, for example, are welcome contributions at the very beginning stages of this journey.

\section{Acknowledgments}

The editors thank the contributing authors for their assistance through the production of the journal and António Vieira, from Cogitatio Press, for his support throughout.

\section{Conflict of Interests}

The authors declare no conflict of interests.

\section{References}

Akyelken, N. (2017). Mobility-related economic exclusion: Accessibility and commuting patterns in industrial zones in Turkey. Social Inclusion, 5(4), 175-182.

Australian Bureau of Statistics. (2017). Household expenditure survey, Australia: Summary of results (201516, Cat. 6530.0). Retrieved from http://search.abs. gov.au/s/search.html?query=household+expenditure +survey+2017\&collection=abs\&form=simple\&profile $=$ default

Buhr, F., \& McGarrigle, J. (2017). Navigating urban life in Lisbon: A study of migrants' mobilities and use of space. Social Inclusion, 5(4), 226-234.

Bureau of Labor Statistics. (2017). Consumer expenditures 2016. Retrieved from https://www.bls.gov/ news.release/cesan.nro.htm

Cao, D., Stanley, J., \& Stanley, J. (2017). Indicators of socio-spatial transport disadvantage for inter-island transport planning in rural Philippine communities. Social Inclusion, 5(4), 116-131.

Cervero, R. (2013a). Linking urban transport and land use in developing countries. The Journal of Transport and Land Use, 6(1), 7-24.

Cervero, R. (2013b). Transport infrastructure and the environment: Sustainable mobility and urbanism. Paper presented at 2nd Planocosmo International Conference, Bandung Institute of Technology, Indonesia, 21-22 October 2013.

Currie, G., \& Delbosc, A. (2011). Field survey results. In G. Currie (Ed.), New perspectives and methods in transport and social exclusion research (pp. 133-156). Bin- 
gley: Emerald.

Currie, G., \& Senbergs, Z. (2007). Exploring forced car ownership in metropolitan Melbourne, Paper presented at the 30th Australasian Transport Research Forum 2007, Melbourne, Australia.

Gakenheimer, R., \& Dimitriou, H. T. (2011). Introduction. In H. T. Dimitirou \& R. Gakenheimer (Eds.), Urban transport in the developing world: A Handbook of policy and practice (pp. 3-7). Cheltenham: Edward Elgar.

Hickman, R., Cao, M., Mella Lira, B., Fillone, A., \& Bienvenido Biona, J. (2017). Understanding capabilities, functionings and travel in high and low income neighbourhoods in Manila. Social Inclusion, 5(4), 161-174.

Hussain, A., Fisher, D., \& Espiner, S. (2017). Transport infrastructure and social inclusion: A case study of tourism in the region of Gilgit-Baltistan. Social Inclusion, 5(4), 196-208.

Marchetti, C. (1994). Anthropological invariants in travel behaviour. Technical Forecasting and Social Change, 47(1), 75-78.

Mattioli, G. (2017). 'Forced car ownership' in the UK and Germany: Socio-spatial patterns and potential economic stress impacts. Social Inclusion, 5(4), 147-160.

Mollenkopf, H., Marcellini, F., Ruoppila, I., Szeman, Z., \& Tacken, M. (Eds.). (2005). Enhancing mobility in later life: Personal coping, environmental resources and technical support: The out-of-home mobility of older adults in urban and rural regions of five European countries. Amsterdam: IOS Press.

National Institute of Economic and Industry Research. (2010). Complementary policies for greenhouse gas emissions abatement and their national and regional employment consequences. Clifton Hill: NIEIR.

Nussbaum, M. (1999). Sex and social justice. Oxford: Oxford University Press.

O’Brien, J., García Vélez, L., \& Zaltz Austwick, M. (2017). Visualizing the impacts of movement infrastructures on social inclusion: Graph-based methods for observing community formations in contrasting geographic contexts. Social Inclusion, 5(4), 132-146.

Office of National Statistics. (2017). Family spending in the UK: Financial year ending March 2016. Retrieved from https://www.ons.gov.uk/peoplepopulationand community/personalandhouseholdfinances/expendit ure/bulletins/familyspendingintheuk/financialyear endingmarch2016

Perez-Barbosa, D., \& Zhang, J. (2017). Transport-based social exclusion in rural Japan: A case study on schooling trips of high school students. Social Inclusion, 5(4), 235-250.

Philippine Statistics Authority. (2017). Family income and expenditure survey, 2015 FIES (Additional tables Table 6). Retrieved from https://psa.gov.ph/ content/2015-fies-additional-tables

Rawls, J. (1971). A theory of justice. Cambridge, MA: Har- vard University Press.

Ryff, C. (1989). Happiness is everything, or is it? Exploration on the meaning of psychological well-being. Journal of Personality and Social Psychology, 57, 1069-1081.

SAFETEA. (2005). The safe, accountable, flexible and efficient transportation equity act of 2003. Retrieved from http://www.fhwa.dot.gov/reauthorization/safe tea_bill.htm

Sen, A. (1993). Capability and well-being. In M. Nussbaum \& A. Sen (Eds.), The quality of life (pp. 30-53). Oxford: Clarendon Press.

Social Exclusion Unit. (2003). Making the connections: Final report on transport and social exclusion. London: Social Exclusion Unit.

Sperling, D., \& Gordon, D. (2009). Two billion cars: Driving towards sustainability. Oxford: Oxford University Press.

Stanley, J. R., \& Banks, M. (2012). Transport needs analysis for getting there and back: Report for Transport Connections: Shires of Moyne and Corangamite. Melbourne: Victorian Government.

Stanley, J. K., Hensher, D., Stanley, J. R., \& Vella-Brodrick, D. (2011). Mobility, social exclusion and well-being: Exploring the links. Transportation Research A, 45(8), 789-801.

Stanley, J., \& Stanley, J. (submitted for publication). Social exclusion: The role of mobility and bridging social capital in regional Australia.

Stanley, J. K., Stanley, J. R., \& Hansen, R. (2017). How great cities happen: Integrating people, land use and transport. Cheltenham: Edward Elgar.

Statistics Canada. (2017). Survey of household spending 2015. Retrieved from http://www.statcan.gc.ca/ daily-quotidien/170127/dq170127a-eng.htm

Statistics Japan. (2017). Summary of the latest month on family income and expenditure survey (September 2017 Table 2). Retrieved from http://www.stat.go.jp/ english/data/kakei/156.htm

United Nations. (2015). Sustainable Development Goals. Retrieved from https://sustainabledevelopment.un. org/sdgsproposal

Vella-Brodrick, D., \& Stanley, J. (2013). The significance of transport mobility in predicting well-being. Transport Policy, 29, 236-242.

Viry, G., Ganjour, O., Gauthier, J.-A., Ravalet, E., \& Widmer, E. (2017). Analysing the role of social visits on migrants' social capital: A personal network approach. Social Inclusion, 5(4), 209-225.

Yamamoto, F. J., \& Zhang, J. (2017). The kindness of strangers: Exploring interdependencies and shared mobilities of elderly people in rural Japan. Social Inclusion, 5(4), 183-195.

Zahavi, A. (1979). The UMOT project. Washington, DC: US Ministry of Transport. 


\section{About the Authors}

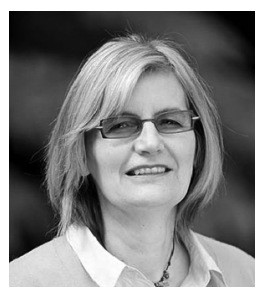

Janet Stanley is a Principal Research Fellow at the Melbourne Sustainable Society Institute, Faculty of Design, the University of Melbourne. She is a Director of the National Centre for Research in Bushfire and Arson and a Director of Stanley and Co., consultants in sustainable policy. Janet specialises in social inclusion, transport, climate change and equity and bushfire arson. She has 80 refereed journal and book publications.

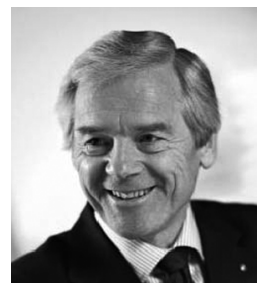

John Stanley is an Adjunct Professor at the Institute of Transport and Logistics Studies (ITLS) at University of Sydney Business School. He is a former Deputy Chair of Australia's National Road Transport Commission. John has published widely on transport and land use policy and planning and is co-author of the books, An Introduction to Transport Policy and How Great Cities Happen. 